\title{
O JOGO LABIRINTO DA TABUADA: UMA EXPERIÊNCIA DE INSUBORDINAÇÃO CRIATIVA COM ALUNOS DO 9 ANO DO ENSINO FUNDAMENTAL II.
}

\section{THE LABYRINTH OF THE TABUADA GAME: AN EXPERIENCE OF CREATIVE INSUBORDINATION WITH STUDENTS OF THE 9TH YEAR OF FUNDAMENTAL EDUCATION II}

\author{
Elisangela Pavanelo \\ Universidade Estadual Paulista (UNESP), Campus de Guaratinguetá \\ elisangela.pavanelo@gmail.com \\ Fernanda Morano de Jesus \\ Universidade Estadual Paulista (UNESP), Campus de Guaratinguetá \\ fernandamorano04@gmail.com \\ Higor Matheus da Silva Soares \\ Universidade Estadual Paulista (UNESP), Campus de Guaratinguetá \\ higorcvb@gmail.com
}

\begin{abstract}
Resumo
Este artigo tem como objetivo apresentar a análise de uma experiência desenvolvida com alunos de uma turma de 9ำ Ano, de uma escola pública da zona rural de Guaratinguetá-SP. Esta experiência é parte do projeto PIBID, vinculado ao curso de Licenciatura em Matemática da Universidade Estadual Paulista, Campus de Guaratinguetá. Em parceria de observação com a professora de Matemática da turma, se constatou a dificuldade dos alunos em relação às tabuadas e que tal dificuldade comprometia o aprendizado de outros conteúdos da grade curricular. Foi solicitado pela professora, aos licenciandos, participantes do PIBID, a ideia de um projeto que auxiliasse os alunos nesse sentido. Propomos então o material "Labirinto da Tabuada", uma adaptação de um jogo eletrônico. Entendemos que atitudes como essa da professora, que procura desenvolver uma atividade diferenciada, mesmo se tratando de um conteúdo que não consta no plano daquele ano letivo e mais, que poderia ser considerado já apresentado aos alunos, se constitui um ato de insubordinação criativa, pois com esta ação promoveu uma aprendizagem na qual os estudantes atribuam significados ao conhecimento matemático. Com o desenvolvimento da atividade a professora procurou auxiliar os alunos, em relação a um conteúdo teoricamente simples, de maneira não discriminatória.
\end{abstract}

Palavras-chave: PIBID, Educação Matemática, Insubordinação Criativa, Jogos no ensino de Matemática. 


\begin{abstract}
This article aims to present the analysis of an experience developed with students of a 9th grade class from a public school in the rural area of Guaratinguetá. This experience is part of the PIBID project, linked to the Undergraduate Mathematics course of UNESP Guaratinguetá. In a partnership with the Mathematics teacher of the class, a diagnostic evaluation was carried out in which the difficulty of the students in relation to the tables was verified, and that this difficulty compromised the learning of other contents. It was requested by the teacher, to the graduates, participants of the PIBID, the idea of a project that would help the students in this sense. We understand that attitudes like this one of the teacher, who seeks to develop a differentiated activity, even if it is a content that is not in the plan of that school year and more, that could be considered already presented to the students, constitutes an act of creative insubordination, since with this action promoted a learning in which the students attribute meanings to the mathematical knowledge. With the development of the activity the teacher tried to help the students, in relation to a theoretically simple content, in a non-discriminatory way.
\end{abstract}

Keywords: PIBID, Mathematics Education, Creative Insubordination, Games in Mathematics teaching.

\title{
Introdução
}

A experiência aqui relatada e analisada é parte do projeto PIBID (Programa Institucional de Bolsa de Iniciação à Docência) vinculado ao curso de Licenciatura em Matemática da Universidade Estadual Paulista, Campus de Guaratinguetá. Tal experiência foi vivenciada com uma turma do 9ํano do Ensino Fundamental II, de uma escola pública da zona rural de Guaratinguetá-SP.

O PIBID é uma iniciativa para o aperfeiçoamento e a valorização da formação de professores para atuação na Educação Básica. O programa concede bolsas a alunos de licenciatura participantes de projetos de iniciação à docência desenvolvidos por Instituições de Educação Superior (IES), em parceria com escolas de Educação Básica da rede pública de ensino. Os projetos devem promover a inserção dos estudantes no contexto das escolas públicas desde o início da sua formação acadêmica para que desenvolvam atividades didático-pedagógicas sob orientação de um docente do curso de licenciatura e de um professor da escola (CAPES-MEC, 2008).

O objetivo da atividade, apresentada neste texto, em parceria com a professora de Matemática da turma, foi suprir uma necessidade detectada, em relação ao aprendizado da tabuada. Verificou-se que tal dificuldade comprometia o aprendizado de outros conteúdos da grade curricular. Foi então solicitado pela professora, aos licenciandos participantes do PIBID, que elaborassem um projeto que auxiliasse os alunos nesse sentido. Diante disso, foi elaborado o material "Labirinto da Tabuada", uma adaptação de um jogo eletrônico.

Esta experiência se mostrou relevante à aprendizagem dos alunos, tanto ao levarmos em consideração os dados coletados no seu desenvolvimento, quanto no que se 
refere à prática docente, que não se limitou apenas "aos objetivos previamente determinados, sem considerar o contexto no qual seu aluno está inserido" (D'AMBROSIO e LOPES, 2015, p. 4).

\section{A atividade proposta a partir do Jogo "Labirinto da Tabuada"}

Para o desenvolvimento desta atividade optamos pelo jogo como estratégia de ensino, pois de acordo com Moura (2017) o professor o faz com uma intenção: propiciar a aprendizagem e ao fazer isto tem como propósito o ensino de um conteúdo ou de uma habilidade.

A intenção de trabalhamos com as tabuadas, tido como algo que os alunos já deveriam saber, exigia de nós uma dose extra de cuidado. Por um lado não podíamos infantilizar as atividades propostas, por outro, entendíamos a partir do trabalho de acompanhamento das aulas e dos erros mais comuns apresentados pelos alunos, que este projeto seria importante para a continuidade do conteúdo proposto no decorrer do ano.

Para tanto era necessário que incentivássemos os alunos a elaborar estratégias, questionando as jogadas realizadas para que o jogar se tornasse um momento de aprendizagem e recriação conceitual. Não era do nosso interesse a reprodução mecânica das regras de tabuada, nem mesmo incentivar formas de decorá-la.

Foi necessário focar o trabalho dos alunos na elaboração de processos de análise de possibilidades e tomada de decisão: habilidades necessárias para o trabalho com resolução de problema, tanto no âmbito escolar como no contexto social no qual todos estão inseridos.

Desse modo, poderíamos inserir os alunos em um contexto lúdico, mas ao mesmo tempo em que os incentivasse a colocar seu pensamento em movimento, enfrentando o desafio de elaborar estratégias para resolver o problema, ganhar o jogo.

O objetivo era de que o jogo escolhido permitisse que os alunos compreendessem algumas estratégias relacionadas ao cálculo da tabuada. Utilizamos para isso um jogo adaptado para o tabuleiro que se utiliza pinos e dados, conhecido como "Labirinto da Tabuada". O objetivo do jogo é descobrir o caminho do gol, passando pelas casas que contêm resultados de uma ou das duas tabuadas indicadas do lado direito do tabuleiro. 


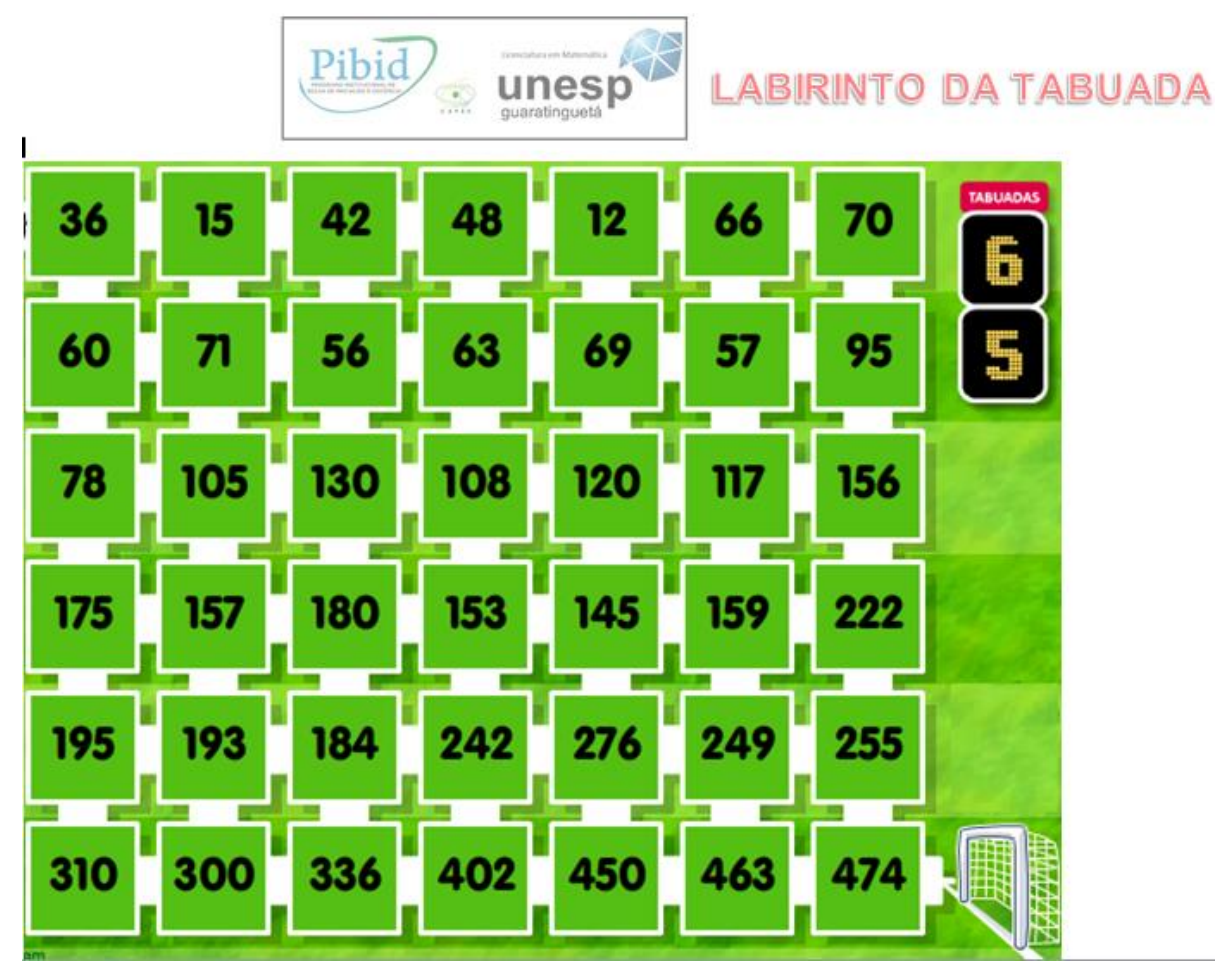

Figura 1 - Tabuleiro do Jogo Labirinto da Tabuada

Fonte: adaptado do site: https://novaescola.org.br/conteudo/4836/labirinto-da-tabuada

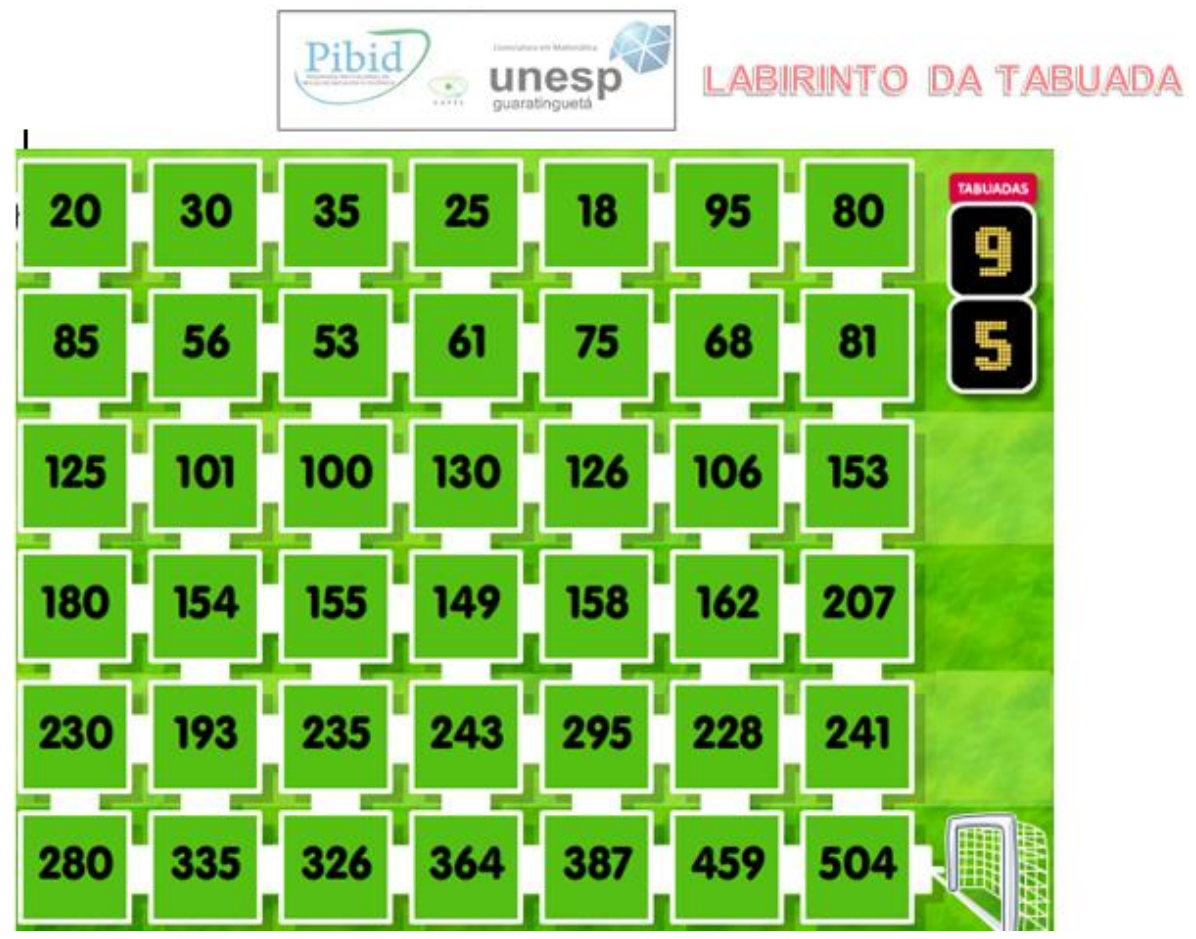

Figura 2 - Tabuleiro do Jogo Labirinto da Tabuada

Fonte: adaptado do site: https://novaescola.org.br/conteudo/4836/labirinto-da-tabuada

As Imagens 1 e 2 ilustram dois dos tabuleiros utilizados. Nestes tabuleiros os alunos realizaram cálculos relacionados às tabuadas do 6 e do 5 , em um deles, e do 9 e do 5 no 
outro, como se pode ver indicadas à direita do tabuleiro, de acordo com as regras que seguem:

- Dois participantes por tabuleiro;

- Começa a partida quem tirar o número maior no dado;

- Para dar início, o jogador deve jogar o dado para saber quantas casas irá avançar ou retroceder, sabendo que deverá passar pelas casas que correspondem aos múltiplos dos números indicados no tabuleiro;

- Caso o jogador caia, ou passe, pela casa que não seja um múltiplo dos números indicados, ele deverá retornar para o início do jogo, sabendo que a verificação fica a critério do outro jogador;

- O primeiro a chegar na última casa, localizada em frente ao gol, torna-se o vencedor.

Já nos outros tabuleiros, os cálculos foram relacionados às tabuadas dos números 4 e $7 ; 2$ e 7 ; e as dos números 8 e 3 . Conservamos o mesmo valor dos tabuleiros utilizados no jogo online que foi utilizado como suporte1.

$\mathrm{Na}$ sala de aula, os alunos foram divididos em duplas e o trabalho se deu de modo que eles jogassem ao menos em dois tabuleiros diferentes2. Orientamos as duplas a fazer registros, no decorrer das jogadas, de suas estratégias de jogo em uma folha a parte. A experiência se deu em 6 aulas. Duas aulas para que os alunos jogassem, duas para que, ainda com os tabuleiros, respondessem às questões apresentadas a seguir, propostas pela professora e as duas aulas finais para as discussões.

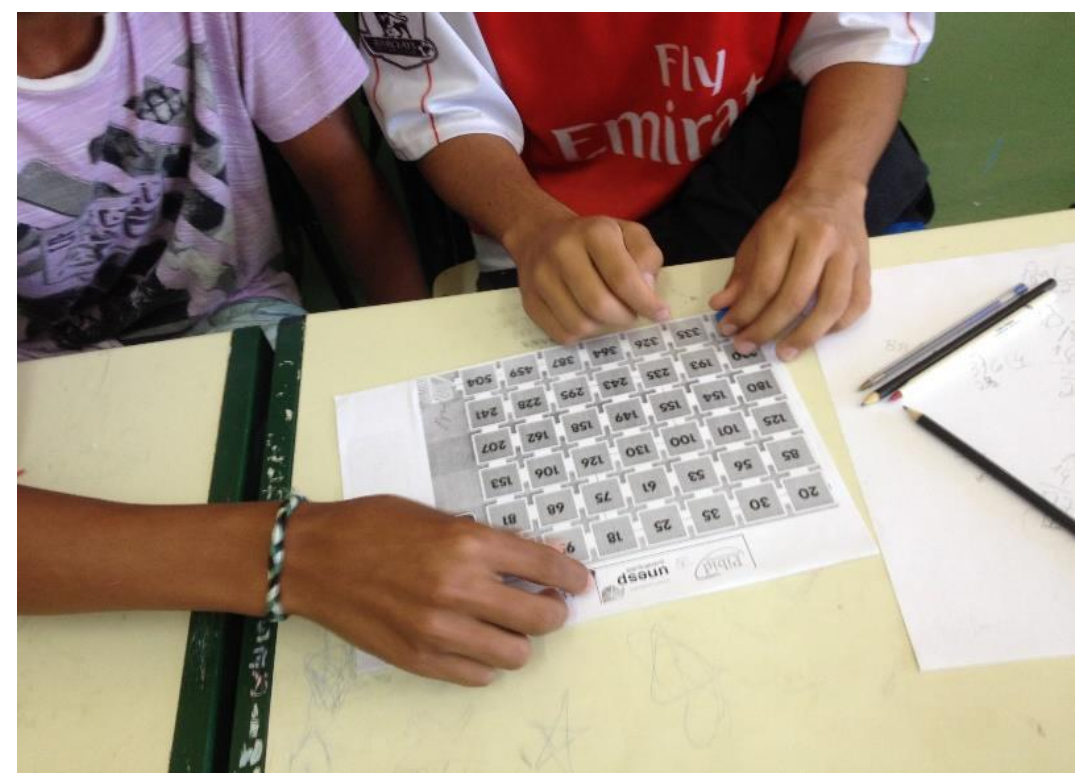

Figura 3 - Alunos durante o jogo

Fonte: Os autores

\footnotetext{
${ }^{1} \mathrm{O}$ jogo online não foi utilizado devido a uma limitação da internet que a escola possui. Após um teste, concluímos que não seria possível desenvolver a atividade dessa maneira.

${ }^{2}$ Os tabuleiros que foram entregues aos alunos eram semelhantes aos das figuras 1 e 2.
} 
Desse modo, ao término das jogadas as duplas responderam, por escrito, aos seguintes questionamentos sugeridos pela professora:

- Qual foi sua estratégia para chegar ao gol?

- Existiu algum tabuleiro que você teve mais dificuldade de chegar ao gol? Ou mais facilidade? Por quê?

- Qual a sua opinião sobre esta atividade desenvolvida nas aulas de Matemática.

Depois de responder a essas questões, foi realizada uma breve discussão dos alunos sobre suas respostas com o objetivo de que as duplas compartilhassem opiniões, principalmente em relação às estratégias para se chegar ao gol.

$\mathrm{Na}$ fala dos alunos surgiu a ideia relacionada aos critérios de divisibilidade, em termos como:

Aluno1: "Você tem que ver o número que dá para dividir... por 2, por exemplo... 0 que dá pra dividir por 2? Tem que ser par.... Agora tem números que é mais difícil descobrir.... tem que ficar tentando... O 7, por exemplo, é mais complicado...

Aluno2: "É quando tem a "casinha" tem só dois números é mais fácil, porque a gente vê se o número tá na tabuada... por exemplo do 9... Mesmo que passa de 90 você vai contando de 9 em 9... Mas assim é mais difícil quando o número da "casinha" é muito grande, 288, por exemplo! Dá por 9?

De maneira geral os alunos se envolveram satisfatoriamente no desenvolvimento do jogo. Já nas discussões foi necessário um certo incentivo para que começassem a se soltar e falar sobre suas impressões

Ao final da discussão a professora fez um fechamento final em relação aos critérios de divisibilidade, trazendo algumas estratégias para os critérios para números divisíveis por 7, por exemplo.

\section{Sobre a insubordinação criativa e a prática desenvolvida}

A obrigatoriedade de se seguir a risca planos de ensino pode ter emergido a partir do texto exposto na LDB (Lei de Diretrizes e Bases) que estabelece, de acordo com seu Artigo 13,

Art. 13. Os docentes incumbir-se-ão de:

I - participar da elaboração da proposta pedagógica do estabelecimento de ensino;

II - elaborar e cumprir plano de trabalho, segundo a proposta pedagógica do estabelecimento de ensino; ${ }^{3}$

III - zelar pela aprendizagem dos alunos;

IV - estabelecer estratégias de recuperação para os alunos de menor rendimento;

\footnotetext{
${ }^{3}$ Grifo dos autores.
} 
$\mathrm{V}$ - ministrar os dias letivos e horas-aula estabelecidos, além de participar integralmente dos períodos dedicados ao planejamento, à avaliação e ao desenvolvimento profissional. (BRASIL, p. 06, 1996).

Observamos, ao analisar o Estatuto do Magistério do Estado de São Paulo, Capítulo XI, Seção II, Artigo 63, que trata dos deveres do integrante do Quadro do Magistério, que não existe nada sobre a obrigatoriedade de se seguir, ou cumprir, integralmente o plano de ensino elaborado 4 .

Algumas instituições, aproveitando de interpretações de leis ou estatutos, tratam o plano de ensino de uma disciplina como algo que deva ser cumprido a qualquer custo, sendo que o seu descumprimento é alvo de punição do docente.

Textos que impregnam o papel do plano de ensino com o conceito de "obrigatoriedade acima de tudo", são encontrados de maneira cada vez mais efetiva no contexto escolar, e em muitos casos, em detrimento à importância do que a LDB deixa bem claro como incumbência do docente: "Zelar pela aprendizagem dos alunos". (BRASIL, p. 06, 1996).

Entendemos que tal instrumento não tem como objetivo fazer um checklist do que foi 0 andamento das atividades durante 0 ano (ou semestre), mas sim o viabilizar 0 desenvolvimento da proposta pedagógica da disciplina, em consonância com os princípios norteadores das políticas educacionais vigentes. Apoia a organização dos processos de ensino e de aprendizagem em sala de aula e permitindo sua avaliação, bem como auxiliando na organização do tempo e materiais utilizados.

Existe então uma diferença entre o cumprimento do plano de ensino, garantindo o direito do aluno ao conteúdo proposto e a obrigatoriedade de seguir uma sequência de conteúdos estipulada em detrimento à qualidade da aprendizagem. Entendemos que uma matriz curricular é uma garantia do direito de acesso ao conhecimento dos alunos, mas o currículo em ação, aquele que o professor exerce na sala de aula é o possível de acontecer. Destacamos então o ato de buscar cumprir uma matriz curricular, mas considerando as condições de ensino e de aprendizagem dos alunos. Reconhecer isso e buscar as possibilidades de fazer os dois acontecerem, representam práticas insubordinadas do professor.

De acordo com Lopes, D’Ambrósio e Corrêa (2016),

os professores são a chave para criar um ambiente de sala de aula com ricas oportunidades para a aprendizagem. É sua a responsabilidade de propor e organizar tarefas e coordenar as atividades de aprendizagem de desenvolvimento para seus alunos. (2016, p. 02).

O foco das nossas discussões nesse trabalho foi sobre a ação de uma professora de Matemática, em conjunto com os alunos do projeto PIBID, de propor em uma turma do

\footnotetext{
${ }^{4}$ Pode ser observada a Lei em sua integra no site:

http://www.al.sp.gov.br/repositorio/legislacao/lei.complementar/1985/lei.complementar-444-27.12.1985.html
} 
9ํano do Ensino Fundamental II, um trabalho com "Tabuada". Tópico este que não consta em seu plano de ensino e que surge nos discursos de alguns pares, como algo que alunos já deveriam saber há tempos.

O professor, de acordo com D’Ambrósio e Lopes (2015),

não deve limitar sua prática docente apenas aos objetivos previamente determinados, sem considerar o contexto no qual seu aluno está inserido. Dessa forma, a atuação docente dependerá de sua sensibilidade para perceber e respeitar o processo de desenvolvimento intelectual e emocional dos alunos. (2015, p. 4).

D’Ambrósio e Lopes (2015) destacam a ideia de Gutiérrez (2013) sobre as manifestações de insubordinações criativas de professores de Matemática, que aponta o questionamento sobre as formas de como a Matemática é apresentada e o desafio dos discursos discriminatórios sobre os alunos, como alguns exemplos.

Consideramos que a prática apresentada neste trabalho constitui um ato de insubordinação criativa, pois "atrever-se a criar e ousar na ação docente decorre do desejo de promover uma aprendizagem na qual os estudantes atribuam significados ao conhecimento matemático" (D'AMBRÓSIO E LOPES, 2015, p. 1).

Com o desenvolvimento desta prática a professora procurou auxiliar os alunos, no que se refere a um conteúdo teoricamente simples, de maneira não discriminatória, usando uma metodologia de trabalho interessante e estruturada de tal forma a posicionar os alunos como corresponsáveis pela sua aprendizagem. Vale destacar que tal prática é resultado de um processo de reflexão crítica da professora, tanto em relação às diretrizes estabelecidas pelas pseudopolíticas públicas, como ao confronto com os dilemas e dificuldades dos alunos. Esse processo de reflexão é destacado por D'Ambrósio e Lopes como precursor da insubordinação criativa.

\section{Considerações Finais}

Este artigo teve o objetivo de apresentar a análise de uma experiência desenvolvida com alunos de uma turma de $9^{\circ}$ Ano, de uma escola pública da zona rural de GuaratinguetáSP. O trabalho descrito e analisado foi parte do projeto PIBID (Programa Institucional de Bolsa de Iniciação à Docência) vinculado ao curso de Licenciatura em Matemática da Universidade Estadual Paulista, Campus Guaratinguetá, em colaboração com a professora da turma.

Consideramos que a proposta da professora, aos alunos do projeto PIBID, de desenvolver uma atividade que tivesse como principal objetivo a retomada dos conteúdos relacionados à Tabuada uma atitude de insubordinação criativa.

A atividade proposta não foi desenvolvida de maneira aleatória, mas sim como resultado da reflexão colaborativa entre os licenciandos participantes do PIBID, a professora da turma e a orientadora institucional. Foi também uma necessidade observada 
por esta professora que não teve como foco da sua ação docente o simples cumprimento do seu plano de ensino, mas, além disso, exerceu uma reflexão acerca da sua prática. Ela não se limitou "aos objetivos previamente determinados, sem considerar o contexto no qual seu aluno está inserido" (D’AMBROSIO e LOPES, 2015, p. 4).

Entendemos que ações como a que foi apresentada neste trabalho, mesmo modestas, mas que evidencia um processo de colaboração entre os educadores matemáticos que atuam na escola e na universidade, e futuros professores de Matemática quando discutida e analisada de maneira crítica, pode ter resultados muito interessantes.

A professora, inicialmente, não tinha consciência da subversidade responsável de sua atitude, essa consciência surgiu após nossas discussões e análises do que havia sido proposto por ela. Desse modo, nossa experiência se mostrou de vital importância tanto para a professora que atua na escola básica, para a professora da universidade e, ainda mais, para os alunos licenciandos. Nossa surpresa foi a compreensão de que experiências tão simples como esta, pode viabilizar uma formação matemática de modo a permitir a todas as pessoas que participaram ampliar suas visões sobre o mundo em que vivem e sentir-se aptos a transformá-lo com vistas à justiça social e à solidariedade. (D'AMBROSIO e LOPES, 2015, p. 14).

Entendemos que esta experiência foi o início do desencadeamento de atitudes reflexivas que nos levarão, não só na busca atividades com significados matemáticos, mas, além disso, buscaremos na sua elaboração e no seu desenvolvimento estimular atitudes que busquem "a construção de um mundo onde todos possam realizar-se com autonomia". (D'AMBROSIO e LOPES, 2015, p. 15).

\section{Referencias}

D’AMBRÓSIO, B.; LOPES, C. Insubordinação Criativa: um convite à reinvenção do educador matemático. Bolema, Rio Claro (SP), v. 29, n. 51, p. 1-17, abr. 2015.

JOGO LABIRINTO DA TABUADA: Disponível em: http://www.atividadesdematematica.com/jogar-jogos-de-matematica/jogo-labirinto-da-tabuada. Acesso em: 20 de abril, 2017.

BRASIL, LDB. Lei 9394/96. Lei de Diretrizes e Bases da Educação Nacional. Disponível em<www.mec.gov.br>. Acesso em: 21 de agosto, 2017.

GUTIERREZ, R. Mathematics teachers using creative insubordination to advocate for student understanding and robust mathematical identities. In: MARTINEZ, M.; CASTRO SUPERFINE, A. (Ed.). Proceedings of the 35th annual meeting of the North American Chapter of the Inter-national Group for the Psychology of Mathematics Education. 35th Chicago, IL: Proceedings... Chicago, IL: University of Illinois at Chicago, 2013.

LOPES, C, D’AMBRÓSIO, B. CORREÂ, S. A.; Insubordinação Criativa em Educação Matemática Promove a Ética e a Solidariedade. Zetetiké, Campinas, SP, v.24, n.3, set./dez. 2016. 
MEC, CAPES. PIBID. Disponível em: http://www.capes.gov.br/educacaobasica/capespibid/pibid. Acesso em: 20 de abril de 2017.

MOURA, M. O. 0 Jogo na Educação Matemática. Disponível em: http://www.crmariocovas.sp.gov.br/pdf/ideias_07_p062-067_c.pdf. Acesso em: 27 de abril, 2017.

Submissão: 17/08/2017

Aceite: 13/11/2017 